\title{
DESCONTINUIDADE ADMINISTRATIVA NA EXECUÇÃO ORÇAMENTÁRIA: CONSEQUÊNCIAS RECORRENTES
}

\author{
Diogo Tadeu Lima Gomes ${ }^{1}$
}

RESUMO: As consequências para sociedade brasileira decorrentes da descontinuidade administrativa na execução orçamentária são o tema principal deste trabalho. A abordagem se desenvolve sob um cenário em que o ciclo político se caracteriza como um traço marcante no setor público brasileiro. Em outras palavras, o trabalho evidencia os prejuízos relacionados a implementação das demandas cada vez mais complexas da população em um contexto de alternância de gestores na administração pública. Uma revisão bibliográfica e documental foi conduzida, à luz, do método descritivo, para subsidiar reflexões em relação a como a sociedade é prejudicada com o ciclo político e os caminhos possíveis para minimizar problemas que ocorrem no setor público brasileiro que tanto afeta a população. Entre considerações finais, isso é oportuno relatar que a promoção de uma ampla reforma política e administrativa visando a unificação das eleições no país e uma maior maturidade da sociedade na hora de eleger; fiscalizar e cobrar de nossos governantes estão entre as vias para que a sociedade avance em relação ao seu bem-estar.

Palavras-chave: Descontinuidade administrativa. Execução orçamentária. Reforma política.

ABSTRACT: The aftermath to brazilian society following the administrative discontinuity of budget execution are the main subject of this presentation. The approach develops over a scenario where the political cycle is characterized as an outstanding trait in Brazil's public sector. In other words, the presentation points the losses related to the implementation of demands more and more complex by the population, in a context on the public administration. A bibliographic and documentary review was conducted in light of the descriptive method, aiming subsidize reflexions about how society is harmed by the political cycle and possible ways to minimize problems that happen there and hurt the population so much. Between final toughts, its proper to relate that the promotion of an ample political and administrative remodeling aiming at the unification of the elections on the nation and more maturity, by part of the population, when it comes to elect someone; inspecting and demanding our governors are among the ways to society advance in relation to its welfare.

Keywords: Administrative discontinuity. Budget execution. Political remodeling

'Pós-graduado em Gestão Pública pela Universidade Estadual de Mato Grosso do Sul e-mail: diogotadeulimagomes@gmail.com. 


\section{INTRODUÇÃO}

Este artigo tem por objetivo debater de maneira simples; clara e objetiva as consequências para a sociedade brasileira decorrentes da descontinuidade administrativa na execução orçamentária em virtude das constantes mudanças dos gestores na administração pública decorrentes de eleições a cada 2 (dois) anos, principalmente quando há trocas em relação a sigla partidária que está comandando a administração pública seja no âmbito federal; estadual, mas particularmente municipal e que conseqüentemente afeta na implementação do planejamento estratégico que visa e busca o bem estar social da população, possibilitando ao final um maior embasamento para uma melhor discussão a respeito do assunto, possibilitando com isso promover as mudanças necessárias no setor público brasileiro.

Quanto à metodologia utilizada na elaboração deste trabalho, foi aplicada a pesquisa de revisão bibliográfica - documental, à luz do método descritivo. A revisão bibliográfica documental é aqui iniciada com o método descritivo, subsidiando reflexões em relação a

como a sociedade brasileira é prejudicada com a descontinuidade administrativa no setor público e quais são os caminhos possíveis para minimizar esses problemas que tanto afeta a máquina pública e particularmente a população.

\section{I.I. Orçamento público}

Esse trabalho apresenta conceitos sobre orçamento público que auxiliará para uma melhor compreensão sobre o tema debatido.

É o instrumento de que dispõe o Poder Público (em qualquer de suas esferas) para expressar, em determinado período, seu programa de atuação, discriminando a origem e o montante dos recursos a serem obtidos, bem como a natureza e o montante dos dispêndios a serem efetuados (PISCITELLI e TIMBÓ, 2009, p. 29).

Conforme Piscitelli e Timbó nos apresenta acima, o orçamento público é um instrumento utilizado pelo poder executivo (federal; estadual ou municipal) que contém a estimativa das receitas e fixa as despesas que serão realizadas durante um determinado exercício financeiro, isto é, o orçamento público é um documento no qual o Governo estima suas receitas e fixa suas despesas para o exercício financeiro de determinado ano. 


\title{
1.2. LEI № 4.320/1964 - Lei de normas gerais de direito financeiro
}

Após uma breve explanação sobre orçamento público abordaremos as leis que norteiam nossos gestores na utilização dos recursos públicos em prol do bem estar social da população.

Começaremos abordando a Lei de Normas Gerais de Direito Financeiro ou simplesmente Lei $\mathrm{n}^{\mathrm{o}}$ 4.320/64.

De acordo com Piscitelli e Timbó (2009, p. 8-9):

\begin{abstract}
A Lei no $4 \cdot 320$, de 17-3-64, recepcionada pela Constituição de 1988 com status de lei complementar, ainda é o diploma básico aplicável, embora deva ser ajustada aos avanços verificados na ciência contábil e incorporados pelas empresas privadas no Brasil nas últimas décadas. [...]. A Lei $\mathrm{n}^{\mathrm{o}}$ 4.320/1964 estatui normas gerais de Direito Financeiro para elaboração e controle dos orçamentos e balanços da União, dos Estados, dos Municípios e do Distrito federal.
\end{abstract}

Concluímos que essa Lei $\mathrm{n}^{\circ} 4.320$ de 17 de março de 1964 estabeleceu normas para elaboração e controle dos orçamentos e balanços tanto da União como estados e municípios, ou seja, a Lei $\mathrm{n}^{\mathrm{o}} 4.320 / 64$ normatiza as finanças públicas do país, diferentemente da LRF que estabeleceu critérios a serem seguidos em relação aos gastos públicos, voltada diretamente para gestão fiscal, conforme iremos verificar e detalhar melhor posteriormente.

\section{I.3.Lei de responsabilidade fiscal (LRF)}

Após uma pequena explanação sobre a Lei $\mathrm{n}^{\mathrm{o}}$ 4.320/64 falaremos mais detalhado sobre a Lei de Responsabilidade Fiscal (LRF) de 04 de maio de 2000 que é uma Lei primordial para as finanças públicas do Brasil.

Segundo Paludo (2013), a Lei Complementar no IOI/2000, mais conhecida como (LRF) foi um divisor na história das finanças públicas do país, visto que estabeleceu critérios a serem seguidos em relação aos gastos públicos, ou seja, deve haver um planejamento na utilização dos recursos públicos tanto no âmbito federal, estadual e municipal, incluindo os poderes executivos, legislativos e judiciários e todos seus Órgãos e Entidades, inclusive empresas estatais dependentes. A LRF foi inspirada principalmente nos Estados Unidos (1990); União Européia (1992); Nova Zelândia (1994); Comunidade Econômica Européia e no Fundo Monetário Internacional (FMI), orientando a conduta 
dos administradores públicos impondo regras e limites (controle dos gastos) e exigindo a prestação de contas na utilização dos recursos públicos além de possibilitar a responsabilização e aplicação de sanções pessoais.

Resumindo o que foi apresentado pelo autor, a LRF veio para estabelecer um padrão a ser seguido por cada ente federativo na utilização dos recursos (possibilitando maior transparência no que diz respeito aos gastos públicos), orientando a conduta dos gestores públicos para que haja uma administração eficiente; eficaz e efetiva, além de impor regras e limites nos gastos permitindo inclusive que sejam responsabilizados e sofram sanções, sendo influenciada em experiências de outros países.

De acordo com Sales e Martins (2014), na LRF destaca-se alguns pilares importantes para que de fato haja equilíbrio das contas públicas, e entre esses pilares que veremos e abordaremos na figura abaixo encontramos o planejamento; controle dos gastos; transparência e responsabilização.

Figura I - Pilares da Lei de Responsabilidade Fiscal.

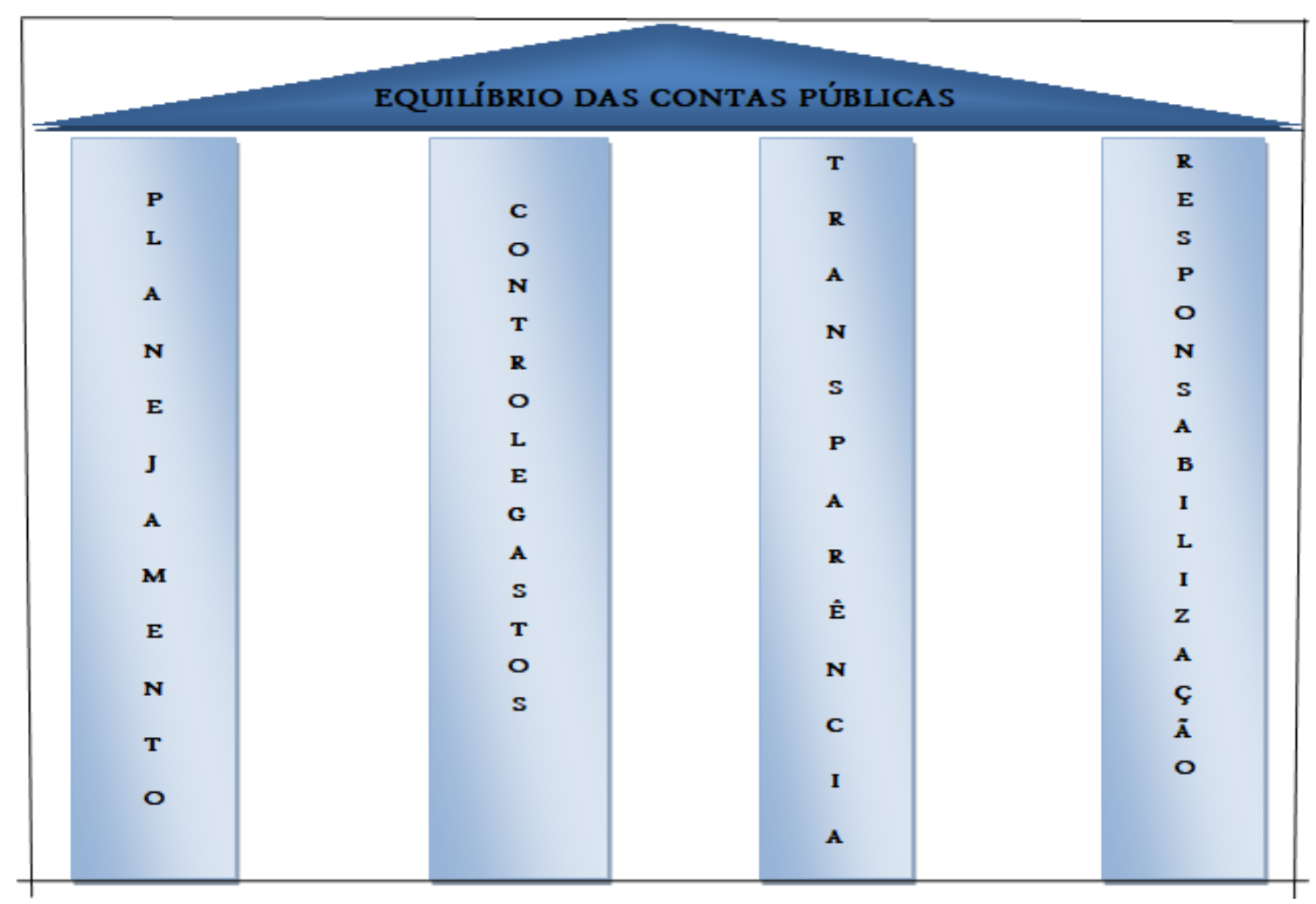

Fonte: Elaboração Própria. 
A figura exibe os pilares importantes da LRF para que realmente ocorra o equilíbrio das contas públicas, ou seja, primeiramente é necessário que haja um planejamento por parte dos administradores na utilização dos recursos públicos, sabendo em quais áreas o dinheiro pode ser aplicado e o quanto desse recurso deve ser destinado a cada programa e projetos, seja na esfera federal, como estadual ou municipal, posteriormente é fundamental o controle dos gastos por isso verificamos que há regras e limites que os gestores devem seguir, por esse motivo é fundamental que o planejamento seja bem executado para que os limites não sejam extrapolados. Outro pilar importante diz respeito a transparência, onde é exigido a prestação de contas por parte dos gestores públicos aonde os recursos estão sendo empregados e quanto desses recursos estão sendo destinados para cada área como, por exemplo, saúde, educação. Outro ponto importante da LRF refere-se a responsabilização e aplicação de sanções aos administradores que não utilizam os recursos de maneira correta visando o bem estar social da população, entre essas sanções encontramos o a cassação do mandato; detenção entre outras.

\subsection{PLANO PLURIANUAL (PPA)}

Paulo (2010, p. 2) coloca que:

O Plano Plurianual é uma lei, de iniciativa do Poder Executivo, que deve estabelecer, "de forma regionalizada, as diretrizes, objetivos e metas da administração pública federal para as despesas de capital e outras delas decorrentes e para as relativas aos programas de duração continuada" (CF/88, art. I65, $\S^{\mathrm{I}^{\mathrm{o}}}$ ).

Conforme apresentado por Paulo, o PPA é uma peça fundamental para administração pública, pois orienta o orçamento anual do Governo contemplando as ações que serão implementadas através de metas e programas de trabalho, isto é, define as diretrizes, metas e objetivos da administração pública num período de médio prazo. $\mathrm{O}$ PPA tem duração de 4 (quatro) anos e sua vigência começa a partir do segundo ano de mandato do poder executivo encerrando-se no primeiro ano de mandato do governo subseqüente, isso ocorre para possibilitar que o próximo governante tenha acesso a real situação financeira deixada pela administração anterior e garantir também que o novo governante de continuidade aos programas e projetos iniciados na gestão passada. 
Portanto, o PPA é o instrumento de maior hierarquia dentro do conjunto de planejamento em qualquer entidade da administração pública, seja ela federal; estadual ou municipal, e em função disso as demais leis devem se submeter as diretrizes; objetivos e metas que foram estabelecidos, e é por meio do PPA que orçamento anual é orientado para que sejam implementadas as metas e os programas de trabalho da administração pública, buscando atender da melhor maneira as demandas da sociedade.

\subsection{LEI DE DIRETRIZES ORÇAMENTÁRIAS (LDO)}

Paludo (2013, p. 73) apresenta que:

A Lei de Diretrizes Orçamentárias - LDO é o instrumento norteador da elaboração da LOA - Lei Orçamentária Anual. Ela seleciona os programas do Plano Plurianual que deverão ser contemplados com dotações na LOA correspondente. A LDO também se materializa numa lei ordinária de iniciativa privada do chefe do Poder Executivo. É um instrumento de planejamento e o "elo" entre o PPA e a LOA. Ela antecipa e orienta a direção e o sentido dos gastos públicos, bem como os parâmetros que devem nortear a elaboração do Projeto de Lei Orçamentária para o exercício subseqüente, além, é claro, de selecionar, dentre os programas do Plano Plurianual, quais terão prioridade na programação e execução do orçamento anual subseqüente.

A respeito da LDO fica claro que essa lei orienta a elaboração da LOA para o exercício financeiro seguinte. A LDO é a ligação entre os programas previstos no PPA e os que realmente serão executados na LOA, em resumo, a LDO leva para a LOA aquelas metades e objetivo que foram definidos no PPA, estabelecendo as metas e as prioridades (programas) do governo para cada exercício financeiro.

\subsection{LEI ORÇAMENTÁRIA ANUAL (LOA)}

Finalizando as principais leis que norteiam os governantes brasileiros na utilização dos recursos públicos destacaremos a Lei Orçamentária Anual (LOA).

Nascimento e Debus (200o, p. 19) nos apresenta que:

A Lei Orçamentária Anual, prevista no artigo 165 , parágrafo $5^{\circ}$ da Constituição Federal, constitui o mais importante instrumento de gerenciamento orçamentário e financeiro da Administração Pública, cuja principal finalidade é administrar o equilíbrio entre receitas e despesas públicas.

Em outras palavras, a LOA é a lei que possibilita que tudo aquilo que foi planejado no PPA seja efetivamente concretizado pela administração, obedecendo o que foi previsto 
na LDO e com isso estabelecendo os programas que serão executados em busca do bem comum da sociedade, prevendo todas as receitas disponíveis e fixando as despesas públicas.

$\mathrm{Na}$ figura abaixo observaremos uma visão simplificada do orçamento público.

Figura 2 - Visão Jurídico-Legal do Orçamento Público.

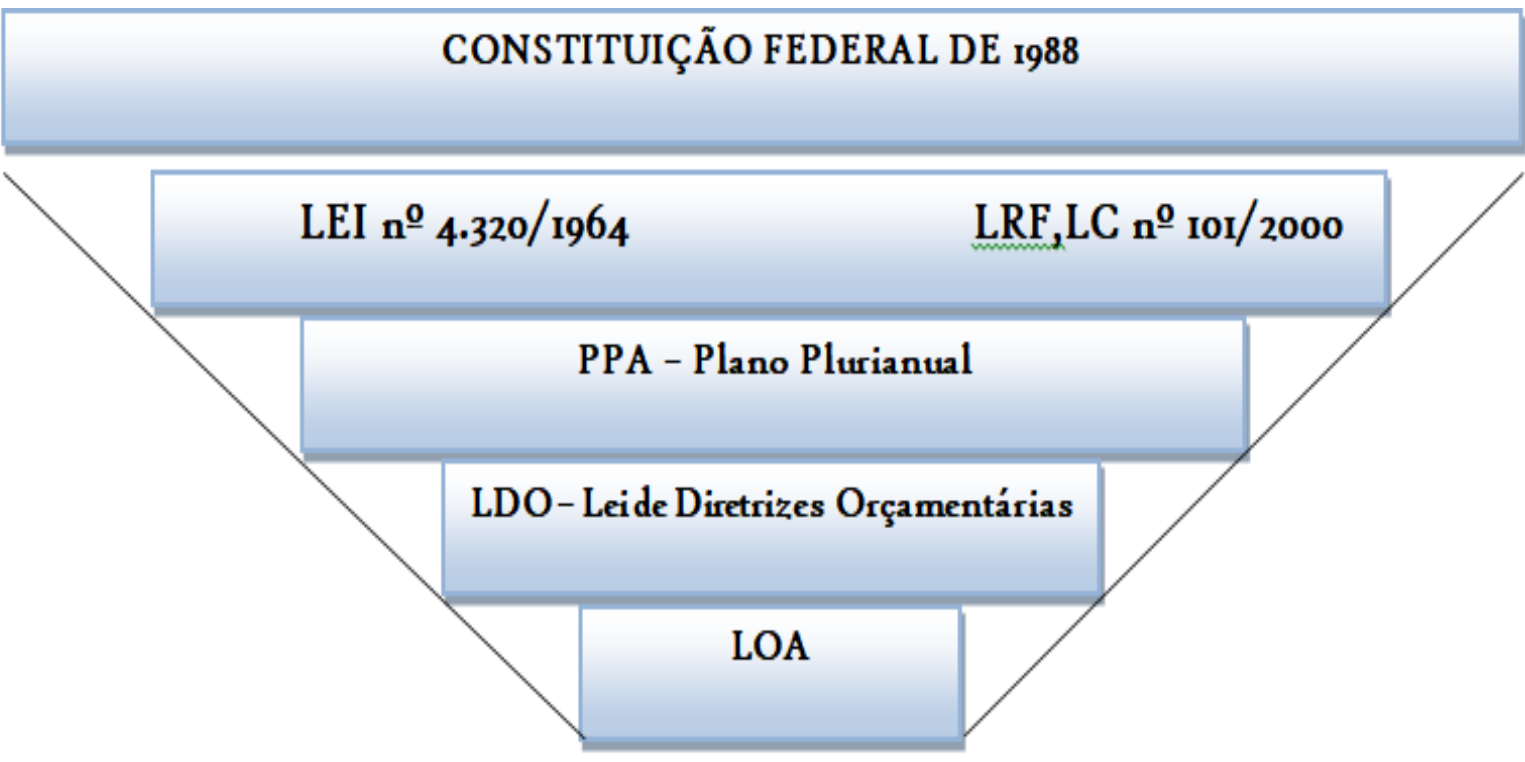

Fonte: Paludo (2013, p. 48).

$\mathrm{Na}$ figura fica bem claro que a LOA ocupa um papel inferior em relação as demais legislações, devendo obedecer e seguir aos demais instrumentos legais que possuem o mesmo grau hierárquico, outras que possuem condições de leis complementares, além é claro da LRF e principalmente da Constituição Federal. A LOA cumpre aquilo o que está definido em legislações superiores, de modo que venha a satisfazer e atender as necessidades da população.

\section{DESCONTINUIDADE ADMINISTRATIVA NO SETOR PÚBLICO}

\section{I. Definindo descontinuidade administrativa}

Segundo Estevam (2010), a descontinuidade administrativa é uma das características mais marcantes na administração pública, tanto na esfera federal; estadual ou municipal, sendo mais perceptível nos municípios de pequeno e médio porte, especialmente quando a mesma sigla partidária não continua governando a União ou Estado de determinada região, visto que as eleições no país ocorrem a cada 02 (dois) anos, e conseqüentemente há 
trocas das siglas partidárias que estão comandando a administração pública. A descontinuidade administrativa é considerada como um aspecto normal em qualquer governo democrático, como é o caso do Brasil, onde o poder de decisão está nas mãos dos cidadãos, ou seja, mediante o voto, e é através do voto que ocorre a alternância de poder, permitindo dessa maneira que haja uma renovação na esperança da população de que algo melhor em prol da sociedade possa ser realizado pela nova administração.

Nogueira (2006, P. 15) apud Spink (1987, p. 57) coloca que:

A expressão 'continuidade e descontinuidade administrativa' refere-se aos dilemas, práticas e contradições que surgem na Administração Pública, Direta e Indireta, a cada mudança de governo e a cada troca de dirigentes. Como fenômeno, manifesta-se pelas conseqüências organizacionais de preencher um sem número de cargos de confiança, explícita ou implicitamente disponíveis para distribuição no interior das organizações públicas.

Refletindo sobre o que nos foi apresentado, a descontinuidade está relacionada ao modelo político que se enraizou no setor público brasileiro representado pela troca de favores políticos, mediante aos cargos de confiança (livre nomeação) e não a questões organizacionais.

Pode-se conceber a noção de descontinuidade administrativa, portanto, como as mudanças nas políticas públicas implementadas pelo Estado, mudanças estas decorrentes da substituição do governante por outro de concepção político-ideológica divergente. Essas mudanças nas políticas públicas implicam desde mudanças nas prioridades setoriais de investimentos, até mudanças na estrutura organizacional do aparelho estatal, interrupção e retomada de obras e serviços, tomada de decisões e implementação de programas e projetos, com ou sem a participação popular e de funcionários. (AVRITSCHER, 1995, p. IO-II).

O autor nos mostra que o grande problema ocasionado por esse ciclo político são as mudanças nas prioridades de investimentos; na estrutura organizacional; interrupção de obras, projetos, programas e serviços públicos decorrentes das modificações dos governantes, seja, no âmbito Federal; Estadual ou Municipal, além disso observa-se que tais mudanças na política pública implicam também em modificações em ministérios; secretariados e chefias afetando diretamente aos servidores públicos que ficam confusos com as mudanças de pensamentos e filosofia de trabalho dos novos administradores públicos. 
Estevam (2010, p. 4) apud Nogueira (2006) nos mostra que:

\begin{abstract}
A origem da (des)continuidade de uma maneira mais ampla, estaria ligada ao clientelismo político e ao personalismo característicos do setor público brasileiro. Caracterizada no cargo de confiança - comissionados - e da necessidade a cada nova gestão apresentar "novas" soluções (não necessariamente inovadoras, mas que tenham sua marca). As características da (des)continuidade administrativa ocorre em diversos graus, desde a simples perda de prioridade na agenda de novos gestores até a mudança de nome, objetivos ou estratégias ou a interrupção total de atividades, quase sempre em função de critérios políticos e não-técnicos. Acontece em projetos, programas, políticas e/ou em organizações ou instituições como um todo.
\end{abstract}

A descontinuidade administrativa é um "mal” necessário para o crescimento e desenvolvimento de qualquer governo democrático, pois conforme abordado nesse trabalho renova as esperanças da população de que algo melhor possa ser realizado em benefício da sociedade, porém o que verificamos no setor público brasileiro é que esse “câncer" está ligado diretamente ao clientelismo político e ao personalismo, ou seja, na troca de favores entre políticos objetivando interesses de indivíduos ou grupos com quem mantém relações de proximidade pessoal, em resumo, significa que determinado político ou sigla partidária busca ampliar seu eleitorado e apoio político visando as eleições para determinado cargo em troca de benefícios públicos, especialmente na forma de empregos na administração pública os famosos cargos de confiança (comissionados).

Um aspecto da descontinuidade administrativa observado em algumas regiões é que o novo administrador público não permite que o administrador anterior receba os créditos pela realização de alguma obra ou programa mesmo sendo da mesma sigla partidária, por envolver questões de princípios e métodos dos novos gestores.

\title{
2.2. Características do setor público no brasil
}

As organizações públicas possuem particularidades que as diferenciam das organizações privadas, como por exemplo, não visam lucros e sim promover o bem estar social da população, diferentemente das empresas privadas que visa o melhor resultado possível, mas sem dúvida um dos aspectos que mais diferencia das organizações públicas das organizações privadas é a descontinuidade administrativa, e através dela verifica-se características específicas nas instituições públicas conforme observaremos nos tópicos abaixo abordados por Pires e Macêdo (2006) apud Schall (1997). 
- Projetos de Curto Prazo;

- Duplicação de Projetos;

- Mudanças nos Quadros dos Servidores Públicos;

- Conflitos de Objetivos;

- Administração Amadora.

Entre as características apresentadas encontramos os projetos de curto prazo, onde cada administrador público busca favorecer; beneficiar apenas os projetos que possam concluir dentro do seu respectivo mandato, visando retorno político seja através da reeleição; seja mediante eleição para outro cargo político. Em relação a duplicação de projetos, cada governo novo busca iniciar novos projetos com suas respectivas marcas e muitas vezes são projetos idênticos aos que foram criados pelo seu antecessor, porém esses novos administradores reivindicam para si a autoria desses projetos ou programas, temos por exemplo, o Bolsa Escola; Bolsa Alimentação e Auxílio Gás que posteriormente virou Bolsa Família.

A mudança nos quadros dos servidores públicos especialmente os servidores de livre

nomeação (comissionados), pois são substituídos a cada novo governo, principalmente os cargos de chefia, provocando ajustes importantes no planejamento da organização, as vezes mudando totalmente o rumo das metas e objetivos visando atender as demandas políticas especialmente aos interesses daquele grupo que os indicaram.

Já o conflito de objetivos tem haver com a questão dos servidores pertencentes ao quadro permanente e os não-permanentes da administração, gerando com isso falta de comprometimento e empenho em cumprir a missão, pelo fato de saber que a chefia logo será substituída juntamente com sua equipe e com isso a metodologia de trabalho também será alterada. E por último temos a administração amadora, onde o serviço público é realizado por pessoas com pouco conhecimento e muitas vezes sem a devida experiência e preparo técnico necessário, predominando o clientelismo político em detrimento a capacidade técnica dos servidores nomeados.

\subsection{Conseqüências decorrentes da descontinuidade administrativa}

Conforme apresentamos no início deste trabalho o PPA é uma lei que define as diretrizes, metas e objetivos da administração pública, pois orienta o orçamento anual do 
Governo contemplando as ações que serão implementadas através de metas e programas de trabalho passando a vigorar a partir do segundo ano de mandato do poder executivo encerrando-se no primeiro ano de mandato do governo subseqüente, visando possibilitar que o próximo administrador tenha acesso a real situação financeira deixada pela administração anterior e garantir também que o novo governante de continuidade aos programas e projetos iniciados na gestão passada, porém não é bem isso que acontece na administração pública especialmente em função da descontinuidade administrativa que ocorre no setor público principalmente nos municípios de pequeno e médio porte.

Cabe ressaltar aqui que no Brasil temos eleições a cada 02 (dois) anos e isso tem relação direta com o ciclo político que vivenciamos no país, especialmente quando a mesma sigla partidária não continua governando, pois de certa maneira existe sempre aquele receio de que a nova administração poderá deixar de lado e paralisar obras e projetos já iniciados pela gestão anterior, dando prioridade a projetos e programas novos, servidores efetivos podem ser remanejados das funções que exerciam, no caso das eleições Presidenciais e Governadores o(s) candidato(s) eleito(s) poderá(ão) priorizar recursos para regiões cujos administradores pertençam a mesma sigla partidária, em detrimento daquelas localidades cuja sigla partidária seja da oposição, ou seja, poderá destinar recursos maiores as regiões onde haja a administração por parte do mesmo partido, destinando recursos menores as regiões cuja administração seja da oposição partidária.

A descontinuidade traz inúmeras conseqüências tanto para administração pública como para a sociedade conforme descreve Almeida (2010, p. 7):

A descontinuidade administrativa tem como conseqüência a diminuição da
eficácia do planejamento estratégico e da instituição pública como um todo.
Constantes alterações nos rumos da organização; freqüentes recomeços; fase de
confusão até que os novos ocupantes dos postos se encontrem enraizados; perda
da memória institucional; remanso na presteza causado pela redução do ritmo de
ação em períodos de transição; alteração de projetos já aprovados e sobreposição
de investimentos; são apenas algumas das seqüelas da descontinuidade na
administração pública.

Podemos observar que entre as conseqüências provocadas pela descontinuidade, há uma diminuição na eficácia do planejamento estratégico e da organização pública como um todo, especialmente devido as constantes mudanças de rumo adotados pelos novos administradores, visto que, a administração pública em geral muda seu jeito a cada novo gestor que assume o mandato, impondo seu método de trabalho e suas idéias. 
Avritscher (1995) coloca que a descontinuidade além de afetar a eficácia do serviço público prejudica também o interior da máquina pública, principalmente no que se refere ao último ano de mandato de um governante, definidos como "armadilhas para o governo seguinte". Essas armadilhas a que o autor se refere são os gastos acima dos recursos disponíveis em caixa, principalmente no que se refere a contratação de obras, prejudicando dessa maneira o orçamento para o primeiro ano do próximo governante; pagamento atraso de fornecedores prejudicando dessa maneira principalmente os municípios de pequeno e médio porte, uma vez que a credibilidade do município em relação ao pagamento de suas dívidas perante aos fornecedores fica abalada, provocando dessa maneira redução no número de fornecedores dispostos a atender a administração pública e principalmente a elevação de preços dos produtos e serviços e imposição de regras para aquelas empresas que ainda decidem continuar participando dos processos licitatórios.

$\mathrm{O}$ autor também acrescenta que a mudança entre governos que possuem projetos $\mathrm{e}$ ideologias diferentes causam outros inúmeros inconvenientes como falta de material de consumo; salários dos servidores atrasados; eliminação de projetos da gestão anterior para estabelecer mudança de governo; retirada do Legislativo, de projetos encaminhados pela administração anterior; mudança de logomarca.

Uma coisa importante que se cabe ressaltar a respeito da descontinuidade administrativa e que devemos nos atentar é que no Brasil os pleitos eleitorais ocorrem a cada dois anos, isto, num primeiro momento são disputadas eleições para Governadores e Presidente e num segundo momento eleições municipais, ou seja, quando for o primeiro ano do mandato de Governadores e Presidente já estará no terceiro ano de mandato dos Prefeitos prejudicando a formação de parcerias entre os governos que beneficiem a sociedade, especialmente quando os respectivos governantes não possuem a mesma sigla partidária e nem possuem as mesmas ideologias.

Sem falar que em períodos eleitorais empregos deixam de ser gerados visto que não são permitidos assinaturas de convênios e especialmente contratação de obras 03 (três) meses antes das eleições visando manter a igualdade de oportunidade entre os candidatos que concorrem ao pleito eleitoral, ou seja, a assinatura de convênios e contratação de obras nesse período pode ser considerada como campanha eleitoral antecipada utilizando-se do recurso público para favorecer determinado candidato em detrimento aos demais. Essa 
proibição decorrente do período eleitoral cria uma burocracia enorme engessando dessa maneira a administração pública, principalmente os municípios de pequeno e médio porte que dependem muito dos recursos provenientes da União e/ou dos Estados atrasando dessa maneira o crescimento e desenvolvimento dessas localidades.

Ainda abordando as conseqüências da descontinuidade administrativa, Estevam (2010, p. 4) apud Nogueira (2006) coloca que:

\begin{abstract}
Esse fato se traduz na interrupção de projetos, obras e serviços público; nas mudanças radicais de prioridades que são muito freqüentes. O viés políticopartidário quase sempre se sobressai, aos demais aspectos; planos futuros são menosprezados e considerações sobre possíveis qualidades ou méritos se transformam em ações (dês)continuadas. O resultado desse processo é observado no desperdício de recursos públicos, desestímulos das equipes envolvidas, tensão e a animosidade entre técnicos estáveis e os que entram com as vitórias nos processos eleitorais.
\end{abstract}

Conforme abordado pelo autor a descontinuidade prejudica tanto a administração pública, pelo fato de que há freqüentes mudanças de prioridades desestímulo e frustração por parte dos servidores, mas afeta principalmente a população que observa projetos e programas interrompidos devido aos rumos adotados pela nova administração, ou seja, a demanda da sociedade que a cada dia está mais complexa deixa de ser atendida em função dos interesses políticos que se sobressaem as necessidades de bem estar social da população e porém a principal conseqüência disso é o desvio e desperdício do dinheiro público.

Abaixo vemos um quadro que resume bem o conceito; as características; conseqüências e possíveis medidas que podem ser adotadas para minimizar os efeitos da descontinuidade administrativa.

Quadro I - Resumo sobre descontinuidade administrativa.

\begin{tabular}{|c|l|}
\hline $\begin{array}{c}\text { Categorias de } \\
\text { análise }\end{array}$ & \multicolumn{1}{|c|}{ Descrição } \\
\hline \multirow{5}{*}{ Origem } & $\begin{array}{l}\text { A descontinuidade administrativa de maneira mais ampla está ligada } \\
\text { ao clientelismo e personalismo característicos do setor público } \\
\text { brasileiro. Caracterizado especialmente pelo excesso de cargos de } \\
\text { confiança (comissionados) existentes e da necessidade de cada nova } \\
\text { gestão de apresentar soluções novas (não necessariamente inovadoras, } \\
\text { mas que tenham sua marca). }\end{array}$ \\
\hline Características & $\begin{array}{l}\text { A descontinuidade administrativa ocorre em diversos graus, desde a } \\
\text { simples perda de prioridade na agenda de novos gestores até a } \\
\text { mudanças de nome, táticas, objetivos ou estratégias até a interrupção } \\
\text { total da atividade, sempre em função de critérios políticos e não- }\end{array}$ \\
\hline
\end{tabular}




\begin{tabular}{|c|l|}
\hline \multirow{2}{*}{$\begin{array}{c}\text { técnicos, de mérito. Acontece em projetos, programas, políticas e até } \\
\text { em organizações ou instituições como um todo. Pode ser vista } \\
\text { também como o conflito entre a ação de novos gestores ("políticos") e } \\
\text { o quadro de servidores estáveis ("burocratas"). }\end{array}$} \\
\hline Conseqüências & $\begin{array}{l}\text { A descontinuidade administrativa traz desperdício de recursos } \\
\text { públicos, perda de memória e saber institucional, desmotivação das } \\
\text { equipes envolvidas e exacerbação do conflito entre técnicos e políticos. }\end{array}$ \\
\hline $\begin{array}{c}\text { Fatores que } \\
\text { podem favorecer } \\
\text { a continuidade }\end{array}$ & $\begin{array}{l}\text { Qualidade e mérito técnico da ação, promoção de parcerias, } \\
\text { participação de diversos atores (principalmente da sociedade civil), } \\
\text { desenvolvimento de mecanismos institucionais, planejamento com } \\
\text { visão de longo prazo, reforço da cultura e da identidade } \\
\text { organizacional. }\end{array}$ \\
\hline
\end{tabular}

Fonte: Nogueira (2006).

Apresentaremos um estudo de caso realizado por Estevam em 2009 na cidade de Florianópolis/Santa Catarina que demonstra como a descontinuidade administrativa, principalmente quando se diz respeito a questões de sigla partidárias prejudica a sociedade, onde o autor realizou uma pesquisa sobre a educação de jovens do campo no Estado de Santa Catarina, precisamente sobre as experiências das Casas Familiares Rurais (CFRs). Esse projeto CRFs é desenvolvido em parcerias, envolvendo entidades governamentais (Prefeitura e Estado) respondendo por mais de $80 \%$ dos recursos e entidades nãogovernamentais (associações; sindicatos; entre outras). Conforme relata Estevam (2009), o projeto em questão sofreu com a intervenção político-partidária a cada pleito eleitoral e que a descontinuidade apresenta-se como uma ameaça constante ao desenvolvimento do processo de formação dos jovens do campo. Essa intervenção acontece de duas formas: a primeira é a rotatividade das equipes de professores comprometendo os avanços do movimento, ou seja, essa troca constante dos profissionais leva o projeto a um constante recomeço e as equipes trabalham com receio, pois a cada mudança de governante significa troca da equipe e a segunda é na inconsistente linearidade no repasse dos recursos financeiros para manutenção do projeto, isto significa que não há uma regularidade nos valores repassados para manutenção desse projeto, dependendo muito se Prefeito e Governador pertencem a mesma sigla partidária ou não.

\subsection{Medidas para minimizar a descontinuidade administrativa e seus efeitos}

A descontinuidade administrativa é uma questão muito complexa que envolve inúmeros fatores, como por exemplo, o fato das eleições ocorrerem a cada dois anos; 
fatores culturais do nosso país entre outros e que dificilmente haverá uma solução principalmente a curto prazo, porém tem algumas medidas que podem ser adotadas e que minimizariam os efeitos provocados pela descontinuidade administrativa no setor público brasileiro. A seguir apresentaremos algumas dessas medidas que deveriam ser adotadas.

Tait (2005) nos apresenta algumas medidas que permitem garantir a continuidade no setor público:

\begin{abstract}
Por fim, a maturidade política pode revelar a forma de garantir a continuidade administrativa do setor público, com medidas que possibilitem aprimorar projetos iniciados, completar os inacabados, corrigir distorções, respeitando, sempre, a população beneficiária dessa continuidade. Para tanto, os governos devem: (I) sair da mediocridade da descontinuidade administrativa e, aproveitando as ações iniciadas, aperfeiçoa-las e leva-las adiante; (2) lembrar sempre que o governo é passageiro e quem governa é o povo, que merece respeito por ter confiado no projeto e nas propostas de campanha eleitoral; (3) respeitar as instâncias representativas da comunidade que buscam a melhoria em cada área de atuação, em prol do bem comum. Assim, garantir o respeito ao dinheiro público, significa respeitar a população que é, sempre quem "paga a conta", em todas as situações.
\end{abstract}

Conforme observamos uma medida importante que pode garantir a continuidade administrativa no setor público brasileiro envolve a maturidade política deixando essa mediocridade do clientelismo político, ou seja, essa constante "troca de favores" que conhecemos e que visam apenas atender os interesses de uma pessoa ou de um grupo político ao invés de buscarem atender a demanda da sociedade proporcionam o bem estar social da população, nossos governantes precisam entender que eles foram eleitos por pessoas que confiaram em seus programas e projetos eleitorais, portanto, que realmente governa e possui o "poder" é a população que deposita seu voto de confiança ao invés dos novos administradores públicos acharem que são os todos poderosos e que tudo funciona gira em seu redor, pois o governo passa mas os benefícios para a sociedade continuam eternamente.

Outra visão que verificamos, envolve a vontade política dos governantes, os arranjos institucionais assumidos pelo poder público, o incentivo proveniente da esfera federal e estadual e os avanços na legislação em torno da gestão compartilhada. Estes seriam elementos para a construção de redes institucionais que reúnam diversos atores sociais, envolvendo articulações intersetoriais, intergovernamentais e entre Estado e sociedade civil para amenizar o círculo vicioso da (des)continuidade administrativa e de políticas sociais. Essa atitude deveria passar pela modificação das estruturas e das ações 
organizacionais, provocando mudanças intra e interorganizacionais e levando à formação de novos tipos de organizações, não só na esfera estatal, mas também na sociedade civil, além de organizações que misturam agentes. Essas iniciativas que envolvem parcerias ou alianças tenderiam a permanecer após mudanças de governo, evitando a (des)continuidade na condução de programas e projetos, indicando maior grau de institucionalização. O problema na operacionalização da proposta a ser observado é que as práticas participativas e inovadoras não são verificadas de forma homogênea pelo país, variando até mesmo de um governo para outro num mesmo local. (ESTEVAM, 2010, p. 5 apud FARAH, 2000).

No Brasil, a vitória nas eleições sempre esteve vinculada ao aspecto clientelista de concessões, cargos e outros favores em troca de lealdade política e pessoal, formando dessa maneira um círculo vicioso: "apadrinhamento-eleições-apadrinhamento" tendo por base na troca à gratidão de favor. Desta maneira fica inviabilizado o debate sobre a participação popular e a concretização da cidadania. (ESTEVAM, 20II, p. 6-7 apud OLIVEIRA e SEIBEL, 2006).

A definição de prioridades nos investimentos dos recursos públicos e seu acompanhamento deveria ser feita pela população diretamente envolvida. Dessa forma os resultados esperados pela sociedade seriam alcançados, pois, mesmo mudando os governos, não mudariam as prioridades locais, mantendo uma linha de continuidade e, desta forma, evitando o desperdício de obras inacabadas”. (NOGUEIRA, 2006, apud LIMANA, 1999, p. 4)

Tanto o contexto apresentado por Estevam como por Nogueira nos apresenta outra medida que deveria ser adotada refere-se a parcerias entre o poder público e a sociedade formando uma estrutura onde haveria os agentes públicos e a sociedade envolvidos no mesmo objetivo e dessa maneira permitiria a condução dos programas e projetos iniciados, mesmo após a mudança de governo, porém o aspecto clientelista do apadrinhamento que existe no setor público dificulta a participação popular e consequentemente a cidadania.

Para Sperafico (2013), outra forma e maneira para minimizar os efeitos causados pela descontinuidade administrativa seriam através de uma ampla reforma política e administrativa com a unificação das eleições, visto que os candidatos terão o mesmo período de mandato para trabalharem em sintonia formando assim parcerias entre as três esferas governamentais, além de determinar que os candidatos eleitos cumpram seus 
respectivos mandatos para o qual foram escolhidos, com isso teríamos candidatos melhores qualificados, acabando como o oportunismo existente atualmente, onde é possível observar candidatos eleitos para o cargo de prefeito e após dois anos se candidatam a outro cargo, deixando de lado os munícipes que o elegeram, outra coisa que verificamos é que os candidatos eleitos muitas vezes se preocupam mais com as disputas políticas do que com as suas atividade e obrigações que o cargo lhe impõe, teríamos também redução de custo aos cofres públicos, uma vez que as eleições a cada dois anos representam despesas ao Tribunal Superior Eleitoral (TSE).

Conforme Soares (2012), nos países sérios e onde não existe esse clientelismo político que vemos no Brasil, o jogo político é mantido, ou seja, os funcionários de carreira e realmente qualificados continuam realizando seus respectivos serviços e prol do bem estar social da população, visto que quando o governo muda apenas Secretários e Ministros são substituídos, sem haver a famosa "troca de favor" entre políticos objetivando interesses de indivíduos ou de grupos partidários.

É importante também e interessante que haja leis mais rigorosas e que de fato se cumpram pelos administradores públicos, e caso isso não ocorra que os mesmos sejam punidos severamente, para servir de exemplo, pois atualmente temos, por exemplo, a LRF que prevê a responsabilização e aplicação de sanções pessoais aos gestores públicos que deixem de cumprir os critérios em relação aos gastos públicos, mas que dificilmente verifica-se algum gestor público sendo efetivamente responsabilizado e punido, mediante devolução do dinheiro ou perda e suspensão dos direitos políticos; o PPA que define as diretrizes; metas e objetivos da administração pública pelo período de 04 (quatro) anos e visa garantir que o novo governante de continuidade aos programas e projetos iniciados na gestão passada, mas que em função da descontinuidade administrativa na administração pública o que se observa são obras e projetos inacabados; recursos sendo desperdiçados, não há continuidade dos programas e projetos iniciados, portanto, no papel são leis que deveriam beneficiar a população, mas na realidade essas leis dificilmente são cumpridas, visto que nossa justiça é lenta, e leva anos para julgar e efetivamente condenar esses administradores públicos que não cumprem as leis, e quem perde com isso é a população em geral. 
Talvez a melhor forma de se reduzir os impactos da descontinuidade administrativa seja mediante maturidade da sociedade brasileira, para que isso ocorra, é necessário que haja um maior envolvimento da população na fiscalização da utilização dos recursos e cobrando que esses recursos sejam realmente aplicados em benefícios para a população, da mesma forma é necessário que haja uma maior participação da sociedade em audiências públicas para elaboração do PPA; LDO e LOA que definem as diretrizes e metas, atualmente vemos que a sociedade brasileira se preocupa apenas com carnaval; futebol entre outras coisas sem tanta relevância deixando de lado as questões que realmente importam, como educação; saúde, em função desse pouco e até mesmo nenhum interesse da sociedade é que observa-se esse desmando pelo qual o país está passando, com essa crise política e econômica; corrupção e mais corrupção, aumento diário de impostos que provoca queda de investimentos, aumento de desemprego, falta de compromisso e ética de alguns governantes.

\section{CONCLUSÃO}

A descontinuidade administrativa é um tema muito complexo, que envolve diversos fatores e que é constantemente debatido dentro da administração pública, particularmente em períodos de pleitos eleitorais, sendo mais perceptível em municípios de pequeno e médio porte, especialmente quando ocorre troca da sigla partidária no comando da administração. Conforme apresentamos ao longo desse trabalho, a descontinuidade administrativa é uma característica marcante no setor público, e considerado como algo normal em governos democráticos como ocorre no Brasil, pois permite que haja uma renovação na esperança da população de que algo melhor em benefício da sociedade será realizado pela nova administração.

Neste artigo buscou-se apresentar as características; os fatores que provocam a descontinuidade administrativa no setor público, as conseqüências que esse problema traz tanto para máquina pública, mas principalmente para a sociedade brasileira, assim como os caminhos possíveis para minimizar esses efeitos que tanto prejudica a população.

Diferentemente do que ocorre em países sérios, a descontinuidade administrativa no Brasil tem um caráter cultural, ligado principalmente ao clientelismo político e ao personalismo que são característicos do setor público brasileiro, ou seja, na troca de favores 


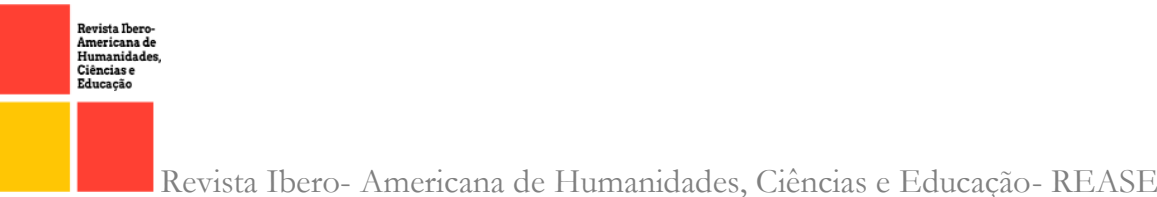

entre políticos objetivando interesses próprios, em troca de benefícios públicos, especialmente na forma de empregos na administração pública os famosos cargos de livre nomeação (comissionados).

Essa prática tão comum e "normal” que ocorre na administração pública, principalmente no Brasil se manifesta mediante a diminuição na eficácia do planejamento estratégico e da organização pública como um todo, devido as constantes mudanças de rumo adotados pelos novos administradores; projetos e obras inacabadas; desmotivação das equipes envolvidas, gerando com isso falta de comprometimento e empenho em cumprir a missão, pelo fato de saber que a chefia logo será substituída juntamente com sua equipe e com isso a metodologia de trabalho também será alterada; falta de profissionais realmente capacitados para executar os serviços, de modo a atender e satisfazer as necessidades da população; além é claro do desvio e desperdício de dinheiro público decorrente das constantes mudanças no rumo da administração pública, adotados pela nova administração.

Ressaltamos que no Brasil as eleições ocorrem a cada dois anos, sem num primeiro momento eleições para Governadores e Presidente e num segundo momento para Prefeitos, e isso afeta mais ainda o andamento do setor público, pois quando for o primeiro ano do mandato de Governadores e Presidente já estará no terceiro ano de mandato dos Prefeitos prejudicando dessa maneira a formação de parcerias entre os governos que beneficiem a sociedade, especialmente quando os respectivos governantes não possuem a mesma sigla partidária e nem possuem as mesmas ideologias, particularmente daqueles municípios de pequeno e médio porte que dependem muito de recursos provenientes do Estado e da União.

Entre os caminhos a serem percorridos para minimizar os efeitos do ciclo político no setor público brasileiro envolve a maturidade política deixando essa mediocridade do clientelismo político, ou seja, nossos governantes precisam entender que eles foram eleitos por pessoas que confiaram em seus programas e projetos eleitorais, portanto precisam buscar atender e satisfazer as necessidades da sociedade, proporcionando dessa maneira o bem estar social da população, ao invés de atender interesses político-partidários.

Outra maneira seria mediante os arranjos institucionais assumidos pelo poder público juntamente com a sociedade civil, dessa maneira, a definição de prioridades nos 
investimentos dos recursos públicos e seu acompanhamento deveria ser feita pela população diretamente envolvida. Dessa forma os resultados esperados pela sociedade seriam alcançados, pois, mesmo mudando os governos, não mudariam as prioridades locais, mantendo uma linha de continuidade e, desta forma, evitando desperdício de dinheiro público com obras e projetos inacabados.

Outra medida importante que deve ser adotada é através de uma ampla reforma política e administrativa com a unificação das eleições, visto que os candidatos terão o mesmo período de mandato para trabalharem em sintonia formando assim parcerias entre as três esferas governamentais, além de determinar que os candidatos eleitos cumpram seus respectivos mandatos para o qual foram escolhidos, impedindo deste modo, por exemplo, que um candidato eleito para o cargo de Prefeito possa dois anos após ser eleito se candidatar a outro cargo político e deixar de lado as pessoas que depositaram confiança em suas propostas e projetos de campanha.

Portanto, a descontinuidade administrativa é um "mal” necessário para o crescimento e desenvolvimento de qualquer governo democrático, pois só dessa maneira as esperanças da população de que algo melhor possa ser realizado em benefício da sociedade são renovadas, visto que, a continuidade administrativa por si só não garante que os serviços serão realmente realizados de modo satisfatório em benefício da população, como pode até mesmo ser prejudicial, conduzindo à acomodação por parte dos governantes, conforme verifica-se atualmente no país em termos de Governo Federal, cujo mandato da sigla partidária já passa de 12 (doze) anos e observamos o país enfrentando uma grave crise econômica, mas principalmente uma crise política sem precedentes.

\section{REFERÊNCIAS}

ALMEIDA, Viviane Lopes da Silva de. Descontinuidade administrativa e efeitos na implementação do planejamento estratégico em instituições públicas. Departamento de Administração Pública. Universidade Gama Filho, Brasília, 20ı. Disponível em < http://lms.eadi.com.br/upload/biblioteca/modulo_1722/UTLQQACJGE.pdf〉.

AVRITSCHER, Harue O. Aspectos da Descontinuidade Administrativa no Processo de Democratização do Executivo Municipal - São Paulo, I986-1992. 1995. IIs f. Dissertação (Mestrado) - Fundação Getúlio Vargas, Escola de Administração de Empresas de São Paulo, São Paulo, i995. Disponível em http://bibliotecadigital.fgv.br/dspace/handle/ro438/5283?show =full $>$. 
ESTEVAM, Dimas de Oliveira. A contínua descontinuidade administrativa e de políticas públicas. II Seminário das Ciências Sociais Aplicadas. Área II - Estado e Políticas

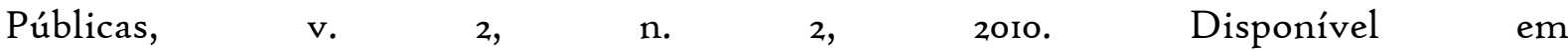
$\langle$ http://periodicos.unesc.net/index.php/seminariocsa/article/viewFile/1390/1317〉.

ESTEVAM, Dimas de Oliveira. A contínua descontinuidade administrativa e de políticas públicas. II Seminário das Ciências Sociais Aplicadas. Área II - Estado e Políticas Públicas, v. 2, n. 2, 2010. Apud FARAH, Marta Ferreira Santos. Governo local, políticas públicas e novas formas de gestão pública no Brasil. Organizações e Sociedade, v.7, n.17, p 59-86, janeiro/abril 2000. Salvador: UFBA/NPGA. 2000. Disponível em 〈http://periodicos.unesc.net/index.php/seminariocsa/article/viewFile/1390/1317〉.

ESTEVAM, Dimas de Oliveira. A contínua descontinuidade administrativa e de políticas públicas. II Seminário das Ciências Sociais Aplicadas. Área II - Estado e Políticas Públicas, v. 2, n. 2, 2010. Apud NOGUEIRA, Fernando do Amaral. Continuidade e Descontinuidade Administrativa em Governos Locais: Fatores que sustentam a ação pública ao longo dos anos. 2006. I39 f. Dissertação (Mestrado) - Fundação Getúlio Vargas, Escola de Administração de Empresas de São Paulo, São Paulo. 2006. Disponível 〈http://periodicos.unesc.net/index.php/seminariocsa/article/viewFile/1390/1317〉.

ESTEVAM, Dimas de Oliveira. A contínua descontinuidade administrativa e de políticas

públicas. II Seminário das Ciências Sociais Aplicadas. Área II - Estado e Políticas Públicas, v. 2, n. 2, 2oro. Apud OLIVEIRA, Heloisa M. J. e SEIBEL, Erni J. Clientelismo e Seletividade: desafios às políticas sociais. In: Revista de Ciências Humanas. Florianópolis. Ed. UFSC, 2006. Disponível em $\langle$ http://periodicos.unesc.net/index.php/seminariocsa/article/viewFile/1390/1317〉.

NASCIMENTO, Edson Ronaldo; DEBUS, Ilvo. Lei Complementar $\mathrm{n}^{\mathrm{o}}$ Ior/2000 Entendendo a Lei de Responsabilidade Fiscal. Tesouro Nacional. 2. ed. Disponível em 〈http://www.fazenda.gov.br/arquivos-economia-servicos/entendendo-a-lei-deresponsabilidade-fiscal/view $>$.

NOGUEIRA, Fernando do Amaral. Continuidade e Descontinuidade Administrativa em Governos Locais: Fatores que sustentam a ação pública ao longo dos anos. 2006. I39 f. Dissertação (Mestrado) - Fundação Getúlio Vargas, Escola de Administração de Empresas de São Paulo, São Paulo. 2006. Disponível em < http://bibliotecadigital.fgv.br/dspace/bitstream/handle/I0438/2423/53706.pdf?sequen>.

NOGUEIRA, Fernando do Amaral. Continuidade e Descontinuidade Administrativa em Governos Locais: Fatores que sustentam a ação pública ao longo dos anos. 2006. I39 f. Dissertação (Mestrado) - Fundação Getúlio Vargas, Escola de Administração de Empresas de São Paulo, São Paulo. 20o6. Apud LIMANA, Amir. O Processo de Descentralização Política - Administrativa no Brasil. Scripta Nova, Barcelona, n. 45 (2I), I de agosto de 1999. Disponível em http://bibliotecadigital.fgv.br/dspace/bitstream/handle/10438/2423/53706.pdf?sequen>. 
NOGUEIRA, Fernando do Amaral. Continuidade e Descontinuidade Administrativa em Governos Locais: Fatores que sustentam a ação pública ao longo dos anos. 2006. I39 f. Dissertação (Mestrado) - Fundação Getúlio Vargas, Escola de Administração de Empresas de São Paulo, São Paulo. 2006. Apud SPINK, Peter. Continuidade e descontinuidade em organizações públicas: um paradoxo democrático. Cadernos Fundap, São Paulo, Ano 7 , n.13, p.57-65, Abril, 1987. Disponível em http://bibliotecadigital.fgv.br/dspace/bitstream/handle/10438/2423/53706.pdf?sequen>.

PALUDO, Augustinho Vicente. Orçamento público, AFO e LRF - Teoria e Questões. 4. ed. - Rio de Janeiro: Elsevier, 2013.

PAULO, Luiz Fernando Arantes. O PPA como Instrumento de Planejamento e Estratégia. Revista do Serviço Público, v.6ı, n.2, p.I71-187, Abril-Junho, 2010. 17 página(s). Disponível em <http://www.spell.org.br/documentos/ver/35685/o-ppa-como-instrumento-deplanejamento-e-gestao-estrategica/i/pt-br $>$.

PIRES, José Calixto de Souza; Macêdo, Kátia Barbosa. Cultura Organizacional em Organizações Públicas no Brasil. Revista de Administração Pública, v.40, n.I Rio de Janeiro jan./fev. 20o6. Apud SCHALL, E. Public sector succession: a strategic approach to sustaining innovation. Public Administration Review, Washington, D.C., v. 57, n. I, p. 4Io, Janeiro-Fevereiro, $1997 . \quad$ Disponível em 〈http://www.scielo.br/scielo.php?script=sci_arttext\&pid=Soo34$76122006000100005 \& \operatorname{lng}=\mathrm{pt} \& \mathrm{nrm}=$ iso $>$.

PISCITELLI, Roberto Bocaccio; TIMBÓ, Maria Zulene Farias. Contabilidade Pública: Uma Abordagem da Administração Financeira Pública. ı. ed. Revista, Ampliada e Atualizada até Outubro de 2008. São Paulo: Atlas, 2009.

SALES, Tainah Simões; MARTINS, Ana Laís Pinto. Planejamento, Transparência, Controle Social e Responsabilidade na Administração Pública após o Advento da Lei de Responsabilidade Fiscal. Revista do Programa de Pós-Graduação em Direito da Universidade Federal do Ceará, v. 34, n. I, p. 241-257, janeiro-junho, 2014. 17 página(s). Disponível em 〈http://www.periodicos.ufc.br/index.php/nomos/article/viewFile/1212/I176〉.

SOARES, Luiz Mário Simor. A Descontinuidade na Administração Pública, 2012. Disponível em < http://gestaosimples.blogspot.com.br/2012/o6/descontinuidade-naadministracao.html>

SPERAFICO, Dilceu. A unificação das eleições e seus benefícios para o País e a sociedade. 2013. Disponível em $\langle$ http://unale.org.br/index.php?option $=$ com_content $\& v i e w=\operatorname{article} \& \mathrm{id}=2083: \mathrm{a}-$ unificacaodas-eleicoes-e-seus-beneficios-para-o-pais-e-a-sociedade \&catid=4:artigos \&Itemid=5>. 
TAIT, Tânia Fatima Calvi. A descontinuidade administrativa no setor público. Maringá, 2005. Disponível em <http://www.din.uem.br/ tait/Continuidade-adm.pdf $>$. 